\title{
Climate effects and temperature thresholds for Eucalypt flowering: a GAMLSS ZIP approach
}

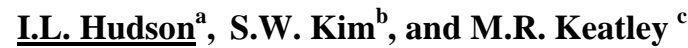 \\ ${ }^{a}$ School of Mathematical and Physical Sciences, University of Newcastle, NSW, Australia \\ ${ }^{b}$ Flinders Centre for Epidemiology and Biostatistics, Flinders University, Adelaide, South Australia \\ ${ }^{c}$ Dept of Forest and Ecosystem Science, The University of Melbourne, Creswick, Victoria, Australia \\ Email: Irene.Hudson@newcastle.edu.au
}

\begin{abstract}
Long-term phenological studies are limited in Australia, and meta-analytic studies of these almost nonexistent (Chambers and Keatley, 2010a,b, Hudson, 2010a, Hudson and Keatley, 2010a). Eucalypts form the focus of known Australian phyto-phenological studies, as they are the dominant species both in a botanical and economic sense. This study extends the Generalised Additive Model for Location, Scale and Shape (GAMLSS) approach to incorporate the zero-inflated (ZIP) Poisson family and to study the flowering records of 8 eucalypt species, Eucalyptus camaldulensis, E. goniocalyx, E. leucoxylon, E. macrorhyncha, E. melliodora, E. microcarpa, E. polyanthemos and E. tricarpaa - with the aim, in part, of detecting non-linear responses to climate. Regardless of the cyclicity of flowering, each species flowering is shown to be significantly influenced by temperature and this effect is non-linear. The main driver for flowering in $E$. leucoxylon, E. macrorhyncha, E. camaldulensis and E. melliodora is minimum temperature with flowering intensity less for E. leucoxylon for warmer minimum temperatures, while flowering intensities increase for the other 3 species in a similar climatic environment; with minimum temperatures in the region under study having decreased significantly by $0.1^{\circ} \mathrm{C}$ between 1998 and 2007. Maximum daily temperature has increased by $0.6^{\circ} \mathrm{C}$ and mean daily temperature by $0.3^{\circ} \mathrm{C}$. More intense flowering is evident in E. goniocalyx and $E$. microcarpa as well as E. polyanthemos, which are positively influenced by mean temperature (for $E$. goniocalyx and E. microcarpa) and maximum temperature (for E. polyanthemos). Flowering in E. tricarpa is expected to be less intense over this period, as it is negatively influenced by maximum temperature and positively influenced by minimum temperatures (after accounting for maximum temperature). Base threshold temperatures were similar for E. camaldulensis, E. melliodora, and E. macrorhyncha, between $8.3^{\circ} \mathrm{C}$ and $9.3^{\circ} \mathrm{C}$; and $9.8^{\circ} \mathrm{C}$ for E. tricarpa. By contrast E. microcarpa has a higher threshold temperature of $16.5^{\circ} \mathrm{C}$, similar E. polyanthemos $\left(17.1^{\circ} \mathrm{C}\right)$ and E. goniocalyx $\left(13.6^{\circ} \mathrm{C}\right)$ - indicating their flowering is in a heatdemanding developmental period (Wielgolaski, 1999). E. polyanthemos has the highest base temperature but the shortest interval, 1 month, between the pre-determined start date and peak flowering. E. leucoxylon commences flowering the latest, with the lowest temperature requirement for development - as supported by its lowest threshold temperature $\left(3.3^{\circ} \mathrm{C}\right.$ ). Of the eight species upper threshold temperatures (when a phase ceases) only one has previously been determined for E. leucoxylon (Hudson et al., 2003). Flowering of all species was positively and significantly correlated with last month's flowering (except for E. macrorhyncha); and with flowering 11-12 months earlier for 4 of the species. There is a clear cycling of the direction of effects of the short term ( $<6$ months) flowering state lags for 3 of the 8 species - E. camaldulensis, E. melliodora and E. polyanthemos. These 3 species had 2-3 month short term lag effects of past flowering (apart from the positive lag 1 effect) that negatively impact on current flowering. For E. polyanthemos there is also a highly significant but opposite, positive 4 month lag effect. These eight species are shown to be significantly influenced by temperature and as a consequence their flowering phenology will possibly change in response to climate change, with changes in temperature likely to translate to changes in both the timing of flowering commencement and intensity. GAMLSS analysis demonstrates the same contemporaneous effect of climate on flowering for E. tricarpa and E. leucoxylon, which constitutes one species pairing; for $E$. goniocalyx, E. microcarpa and E. macrorhyncha; and for E. camaldulensis, E.melliodora and E. polyanthemos, both species triples whose members were shown recently to flower synchronously (Hudson et al., 2011a,b). GAMLSS are thus able to assist in delineating the unique climatic signatures for species which synchronise flowering.
\end{abstract}

Keywords: Multiple Time series, Climate change, Generalised Additive Model for Location, Scale and Shape, Thresholds, Non-linear impacts 


\section{INTRODUCTION}

Phenology (Hudson, 2010a, b): involves the recording of recurring natural events such as the commencement of flowering (Leith 1974, Keatley et al., 1999a, Koch, 2000, Hudson et al., 2005) or the arrival of migratory birds and the influence on such events climatic and edaphic factors; timing of biological events (life stages such as flowering, fruiting, bird arrival) influences many different ecological processes (Forrest and MillerRushing 2010). These processes also have a significant role in shaping society's values (e.g. human health, biodiversity, forestry, agriculture and tourism (Beggs 2004; Fitter and Fitter 2002; van Vliet 2010). Since the 1990s primarily due to climate change (Keatley and Hudson 2010) phenological time series have been used to determine and report the impacts of global warming in both natural and managed systems (Menzel et al., 2006; Rosenzweig et al., 2008; Sparks et al,. 2005). Long-term phenological studies are limited in Australia, and meta-analytic studies of these almost nonexistent (Chambers and Keatley, 2010a,b, Hudson, 2010a,b, Hudson and Keatley, 2010a, Hudson, 2011). Eucalypts form the focus of known Australian phytophenological studies, as they are the dominant species both in a botanical and economic sense (Keatley and Hudson, 2007). The primary aim of this paper is to investigate the relationship between flowering intensity and three temperature variants, minimum, maximum and mean temperature, since temperature is a major climatic influence on phenological events such as flowering (Schwartz, 2000, Snyder et al., 2001) and with rainfall (Hudson et al., 2003, 2005, 2008). This study extends the Generalised Additive Model for Location, Scale and Shape (GAMLSS) approach of Hudson et al. (2009) to incorporate the zero-inflated (ZIP) Poisson family (Lambert 1992) and to study the flowering records of 8 eucalypt species, Eucalyptus camaldulensis, E. goniocalyx, E. leucoxylon, E. macrorhyncha, E. melliodora, E. microcarpa, E. polyanthemos and E. tricarpa - with the aim, in part of detecting non-linear responses to climate. The response of E. leucoxylon has previously been shown to be non-linear (Hudson et al., 2003)

GAMLSS, are part of the Generalized Linear Models (GLM) and Generalized Additive models (GAM) 'family' were developed by Rigby and Stasinopoulos (2005) (Stasinopoulos and Rigby, 2007) to deal with non normally distributed data (e.g. highly skewed, or kurtotic continuous and discrete distributions). Current updates of GAMLSS can deal with up to 50 different types of distributions. Recent applications of GAMLSS involve modelling climate with Sudden Infant Death Syndrome (Hudson et al., 2008) and the establishment of the global standard child growth curves by the WHO (Borghi et al,. 2006) (see also http://en.wikipedia.org/wiki/Generalized_additive model_for_location, scale and shape) and the modelling 4 of the 8 species studied here via GAMLSS with Poisson link (Hudson et al., 2010c; Hudson et al., 2009). The latter represented the first attempt to utilise phenological data to determine the responses of flowering to climate using GAMLSS; and the data set under study represents a long time series by Australasian standards, with more than 30 years of monthly readings, and more than 400 flowering/climate points.

\section{DATA AND METHODS}

Flowering observations were undertaken on a monthly basis at the population level by Forests Commission observers. They categorised their observations of flowering according to the quantity and distribution of flowering across the population. Flowering quantity was ranked from 'No flowering' to 'Heavy flowering', whilst distribution ranges from 'Isolated' to 'General'. Flowering was thus quantified by assigning a rank value to these descriptions according to the formulation in Keatley and Hudson (2007). Flowering intensity (ranging from 0 to 5) was calculated, based on the sum of the quantity and distribution of the rank values, where a score of 0 indicates that no flowering occurred whilst a score of 5 indicated that flowering was heavy and distributed throughout the observation area. These flowering records are the basis of this study, which focus on the flowering of eight species (Keatley at al., 1999, Keatley et al., 2002). Monthly flower counts for flowering intensity and mean monthly readings of climate (minimum and maximum temperature $\left({ }^{\circ} \mathrm{C}\right.$ ), mean diurnal temperature $\left({ }^{\circ} \mathrm{C}\right)$ and rainfall $(\mathrm{mm})$ ) for the historical time period January 1938- March 1972 were collated. The GAMLSS framework of statistical modelling is implemented in a series of packages in $R(R$ Development Core Team, 2007), a free software (see URL http://www.R-project.org). The packages can be downloaded from the R library, CRAN, or from http://www.gamlss.com. For this study the GAMLSS procedure was used with a cubic spline smoothing function and a forwards stepwise stepGAIC function in GAMLSS. Each model tested assumed that the flowering series represent zero-inflated Poisson (ZIP) process and the RS algorithm (Stasinopoulos and Rigby, 2007) was used to obtain the estimates of the climatic predictors. Lagged dependencies of current with past flowering (up to 12 months prior) were added as autoregressive lags. Zero-inflated Poisson (ZIP) models provide a way to model data with excess zeroes. ZIP regression models have been utilised in diverse applications, e.g., modeling fish counts (Mayer et al., 2005). 


\section{RESULTS}

Table 1 shows the results of a GAMLSS ZIP modelling using a forwards stepwise selection procedure via the stepGAIC function in GAMLSS (Stasinopoulos and Rigby, 2007). All effects shown are non-linear effects (cubic splines $(\operatorname{cs}())$ ). From Table 1 we see that the temperature variants had singly (or jointly in the case of E. tricarpa) highly significant $(\mathrm{P}<0.0001)$ non-linear effects on flowering for each species. Rainfall was not a significant factor in predicting flowering intensity after the effects of temperature and previous flowering lags were accounted for (thus it was omitted from the model by the stepwise procedure). Regardless of the cyclicity of flowering over time, this study shows that each species flowering is significantly influenced by temperature and that this effect is non-linear (Table 1).

For each species, except E. macrorhyncha, flowering one month prior significantly increased the likelihood of current flowering (a positive lag1 effect $(\mathrm{P}<0.0001$, Table 1). A significant positive lag effect was found in E. microcarpa and E. polyanthemos, with current flowering positively correlated with flowering one year (lag 12) earlier. Similarly a significant lag 11 effect was found in E. camaldulensis and E. melliodora with current flowering positively correlated with flowering 11 months earlier. There is also a clear cycling of the direction of effects of the short term ( $<6$ months) flowering state lags for 3 of the 8 species, namely, $E$. camaldulensis, E. melliodora and E. polyanthemos. These 3 species had short term lag effects (apart from the positive lag 1 effect of past flowering) that negatively impact on current flowering: at 3 months for both $E$. camaldulensis $(\beta=-1.50, \mathrm{P}<0.0001)$ and E. melliodora $(\beta=-0.24, \mathrm{P}<0.0001)$; and at 2 months for E. polyanthemos $(\beta=-0.17 \mathrm{P}=0.10)$. For $E$. polyanthemos there is also a highly significant but positive lag 4 effect $(\beta=1.24, \mathrm{P}<0.0001)$ - a swap in the sign of the effect of past flowering state between 2 and 4 months (Table 1).

The main climatic driver for flowering, after adjusting for flowering status at earlier lags, in E. leucoxylon, E. macrorhyncha, E. camaldulensis and E. melliodora is minimum temperature - with flowering intensity being less for E. leucoxylon when there are warmer minimum temperatures $(\beta=-0.1024, \mathrm{P}<0.0001)$; whilst flowering increases for the other 3 species in a similar climatic environment; for E. macrorhyncha $(\beta=0.12, \mathrm{P}<0.0001)$; E. camaldulensis $(\beta=0.10, \mathrm{P}<0.0001)$; and E. melliodora $(\beta=0.12, \mathrm{P}<0.0001$, Table 1). Eucalyptus tricarpa flowers less intensely in response to predicted increases in maximum temperature $(\beta=-0.10, P=0.02)$, but more intensely with increased minimum temperature (after accounting for maximum temperature) $(\beta=0.23, \mathrm{P}<0.0001$, Table 1). Eucalyptus tricarpa thus has two main but opposing temperature drivers, in that E. tricarpa prefers cooler maximum temperature but warmer minimum temperature. It is noteworthy that E. leucoxylon flowers less intensely in response to predicted increases in minimum temperature, which have decreased significantly by $0.1^{\circ} \mathrm{C}$ between 1998 and 2007 in the region under study and this species, along with E. tricarpa, are the only species whose main temperature driver has a negative impact on flowering. More intense flowering is evident in E. goniocalyx and E. microcarpa as well as E. polyanthemos, as they are positively influenced by mean temperature (for E. goniocalyx $(\beta=0.19, \mathrm{P}<0.0001)$ and $E$. microcarpa $(\beta=0.17, \mathrm{P}<0.0001)$ and maximum temperature (for $E$. polyanthemos $(\beta=0.08, \mathrm{P}<0.0001)$. All GAMLSS models fitted well (not shown here). E. goniocalyx gave the best fit as evidenced by its low value of scaled deviance statistic (GD = 366.3) (Table 1).

Table 1. Parameter estimates and goodness of fit statistics of the GAMLSS (ZIP2) model for eight species.

\begin{tabular}{llrlrllll}
\hline Species & Predictors & $\beta$ estimate & SE & t value & P & GD $^{\phi}$ & AIC & SBC \\
\hline E. goniocalyx & Intercept & -55.16 & 1.38 & -40.08 & 0.00 & 366.3 & 394.4 & 448.4 \\
& meanT & 0.19 & 0.03 & 6.87 & 0.00 & & & \\
& lag1 & 1.44 & 0.07 & 20.64 & 0.00 & & & \\
\hline E. microcarpa & Intercept & -6.56 & 0.41 & -16.07 & 0.00 & 513.8 & 541.8 & 596.5 \\
& meanT & 0.17 & 0.02 & 8.27 & 0.00 & & & \\
& lag1 & 1.17 & 0.05 & 22.50 & 0.00 & & & \\
& lag12 & 0.31 & 0.06 & 5.18 & 0.00 & & & \\
\hline E. macrorhyncha & Intercept & -1.62 & 0.24 & -6.89 & 0.00 & 663.7 & 675.7 & 698.8 \\
& minT & 0.12 & 0.02 & 4.98 & 0.00 & & & \\
\hline E. camaldulensis & Intercept & -4.31 & 0.59 & -7.35 & 0.00 & 400.5 & 436.5 & 506.1 \\
& minT & 0.10 & 0.05 & 2.12 & 0.03 & & &
\end{tabular}


Hudson et al., Climate effects and thresholds for Eucalypt flowering: a GAMLSS ZIP approach

\begin{tabular}{llrrrrrrr} 
& lag1 & 1.45 & 0.07 & 20.84 & 0.00 & & & \\
& lag3 & -1.50 & 0.03 & -46.22 & 0.00 & & & \\
& lag11 & 2.40 & 0.10 & 23.08 & 0.00 & & & \\
\hline E. melliodora & Intercept & -3.24 & 0.37 & -8.87 & 0.00 & 589.0 & 625.0 & 695.3 \\
& minT & 0.12 & 0.03 & 3.69 & 0.00 & & & \\
& lag1 & 0.61 & 0.05 & 12.41 & 0.00 & & & \\
& lag3 & -0.24 & 0.06 & -3.95 & 0.00 & & & \\
& lag11 & 0.26 & 0.05 & 5.13 & 0.00 & & & \\
\hline E. polyanthemos & Intercept & -5.02 & 0.68 & -7.38 & 0.00 & 501.6 & 545.6 & 631.5 \\
& maxT & 0.08 & 0.03 & 3.28 & 0.00 & & & \\
& lag1 & 0.83 & 0.10 & 8.15 & 0.00 & & & \\
& $\operatorname{lag} 2$ & -0.17 & 0.11 & -1.63 & 0.10 & & & \\
& $\operatorname{lag} 4$ & 1.24 & 0.09 & 13.55 & 0.00 & & & \\
& $\operatorname{lag} 12$ & 0.32 & 0.09 & 3.58 & 0.00 & & & \\
\hline E. leucoxylon & Intercept & 0.40 & 0.17 & 2.33 & 0.02 & 942.0 & 962.0 & 1001.1 \\
& $\operatorname{minT}$ & -0.10 & 0.02 & -5.01 & 0.00 & & & \\
& lag1 & 0.36 & 0.04 & 8.11 & 0.00 & & & \\
\hline E. tricarpa & Intercept & -0.43 & 0.42 & -1.01 & 0.31 & 638.9 & 674.9 & 745.2 \\
& maxT & -0.10 & 0.04 & -2.33 & 0.02 & & & \\
& minT & 0.23 & 0.07 & 3.24 & 0.00 & & & \\
& $\operatorname{lag} 1$ & 0.36 & 0.07 & 5.43 & 0.00 & & & \\
& $\operatorname{lag} 5$ & -0.01 & 0.08 & -0.08 & 0.94 & & & \\
\hline
\end{tabular}

${ }^{\phi}$ GD denotes the scaled deviance statistic; AIC denotes the Akaike information criterion and SBC denotes the Schwarz Bayesian Criterion goodness of fit statistics.

Thresholds for start and finish of flowering: The $\beta$ estimates in Table 1 and the GAMLSS term plot for each model (not shown here) demonstrate the cubic spline effect of each predictor (whether climatic or lag in Table 1) after the other effects in the model have been accommodated for. Reading off the exact temperature at which the spline line and its $95 \%$ confidence limits go above zero for the partial residuals gives the lower temperature threshold for flowering commencement for a given species (e.g. $17.1^{\circ} \mathrm{C}$ maximum temperature for E. polyanthemos, previously $14^{\circ} \mathrm{C}$ by Keatley and Hudson (2000)). Similarly reading off the exact temperature at which the spline curve and its $95 \%$ confidence limits go below zero for the partial residuals gives the higher temperature threshold for finish of flowering for a given species (e.g $26.5^{\circ} \mathrm{C}$ maximum temperature for E. polyanthemos). The resultant temperature thresholds for all eight species show that the base threshold temperatures were similar for E. camaldulensis, E. melliodora, and E. macrorhyncha, between $8.3^{\circ} \mathrm{C}$ and $9.3^{\circ} \mathrm{C}$; and $9.8^{\circ} \mathrm{C}$ for E. tricarpa (previously $11.7^{\circ} \mathrm{C}$ (Keatley and Hudson, 2000)). By contrast $E$. microcarpa has a higher threshold temperature of $16.5^{\circ} \mathrm{C}$, similar to that of E. polyanthemos $\left(17.1^{\circ} \mathrm{C}\right)$ and $E$. goniocalyx $\left(13.6^{\circ} \mathrm{C}\right)$ - indicating that their flowering is in a heat-demanding developmental period (Wielgolaski, 1999). Eucalyptus leucoxylon has the lowest threshold $\left(3.3^{\circ} \mathrm{C}\right)$.

\section{DISCUSSION AND CONCLUSIONS}

This study shows that each specie's flowering is significantly influenced by temperature and that this effect is non-linear. The non-linear effect of temperature is well recognised for crops (Loomis and Connor, 1992) but less so for native species (Sparks et al., 2000). The main driver for flowering in E. leucoxylon, E. macrorhyncha, E. camaldulensis and E. melliodora is minimum temperature. This is in agreement with other studies for E. leucoxylon (Hudson and Keatley, 2010a,b; Hudson et al., 2010; Keatley et al., 2002; Keatley and Hudson, 2000) and E. macrorhyncha (Hudson et al., 2011a,b). The authors found E. macrorhyncha is influenced positively by both minimum and maximum temperatures, with minimum temperatures at the 4 month scale being the most significant. However, the main driver for the other two species has previously been determined to be maximum temperature; and likewise recently by wavelet correlation (but only just significant) (Hudson et al., 2011a,b). Flowering is less for E. leucoxylon for warmer minimum temperatures, 
while flowering increases for the other 3 species in a similar climatic environment. More intense flowering occurs in E. goniocalyx and E. microcarpa as well as E. polyanthemos, as they are positively influenced by mean temperature (for E. goniocalyx and E. microcarpa) and maximum temperature (for E. polyanthemos). E. tricarpa's flowering is expected to be to less over this period, as it is negatively influenced by maximum temperature and positively by minimum temperatures (after accounting for maximum temperature).

Base threshold temperatures (when a plant becomes physiologically active) have not been previously determined for five of these eight species: E. camaldulensis E. goniocalyx, E. macrorhyncha, E. melliodora, and E. microcarpa. GAMLSS ZIP modelling showed that base threshold temperatures were similar for $E$. camaldulensis, E. melliodora, and E. macrorhyncha, between $8.3^{\circ} \mathrm{C}$ and $9.3^{\circ} \mathrm{C}$; and $9.8^{\circ} \mathrm{C}$ for E. tricarpa. By contrast E. microcarpa has a higher threshold temperature of $16.5^{\circ} \mathrm{C}$, similar to that of E. polyanthemos $\left(17.1^{\circ} \mathrm{C}\right)$ and $E$. goniocalyx $\left(13.6^{\circ} \mathrm{C}\right)$. A base temperature of $11.7^{\circ} \mathrm{C}$ for $E$. tricarpa and $14.1^{\circ} \mathrm{C}$ for $E$. polyanthemos (via methods developed by Yang et al. (1995)) - regression coefficient and coefficient of variation $(\mathrm{CV})$ has previously been calculated by Keatley and Hudson (2000). Ranges of a similar magnitude in base temperatures have previously been reported for other eucalypts (e.g. for E. regnans between $5^{\circ} \mathrm{C}$ and $7.5{ }^{\circ} \mathrm{C}$ (Ashton, 1975; Nitschke and Hickey, 2007)). Some of these differences can be attributed to the statistical methods used to determine the threshold temperatures. Indeed a method for evaluating the most appropriate threshold temperatures is yet to receive widespread acceptance (Snyder, 1999). The higher thresholds for E. microcarpa, E. polyanthemos and E. goniocalyx indicate that their flowering is in a heatdemanding developmental period (Wielgolaski, 1999). Eucalyptus polyanthemos has the highest base temperature but the shortest interval, 1 month, between the pre-determined starting date and peak flowering (Keatley and Hudson, 2007). Eucalyptus leucoxylon commences flowering the latest, in May, indicating that it has the lowest temperature requirement for development, as supported by its lowest threshold temperature $\left(3.3^{\circ} \mathrm{C}\right)$. Of the eight species upper threshold temperatures (when a phase ceases - in this case flowering) only one temperature threshold has previously been determined for E. leucoxylon - this using mean temperature an upper threshold of $18^{\circ} \mathrm{C}$ was determined (Hudson et al., 2003).

There is a clear cycling of the direction of effects of the short term $(<6$ months) flowering state lags for $E$. camaldulensis, E. melliodora and E. polyanthemos. For E camaldulensis and E. melliodora their dependency cycled, from positive to negative, from lag 1 to lag 3 months, and oppositely from negative to positive from lag 3 to 11 months prior. These 3 species had significant short term lag effects (apart from the positive lag 1 effect of past flowering state) that negatively impact on current flowering: at 2 months for E. polyanthemos and at 3 months for both E. camaldulensis and E. melliodora - this species triple was recently identified as synchronous (Hudson et al., 2011a,b). The change in direction of the effect of past flowering may well reflect the dynamic cycling impacts of climate and flowering as evidenced by both wavelets (Hudson et al (2010a,b) and singular spectrum analysis (Hudson and Keatley, 2010b) of the same eight species. Also confirmed recently by multivariate mixture approaches (Kim et al., 2011). Lags of 11 and 12 months are intuitively expected given that an annual flowering is expected, but evidenced only in 4 of the 8 species. What differentiates these with later lags versus those without? For each species one can consider a combination of five flowering characteristics: the highest value of the likelihood of flowering commencing in a given month in a flowering year; the number of months that flowering generally starts in; the number of months that flowering generally commences in, the probability of flowering success for a given month each year and how often flowering fails. Two of the species, E. microcarpa and E. melliodora, with late lags have been shown by Keatley and Hudson (2007) to have high values for the likelihood for the month they commence flowering in (>0.60). For the others it is a combination of lower number of months that flowering occurs in or where flowering is spread over, and a low flowering failure rate/high annual flowering success rate. Eucalyptus camaldulensis commences flowering in four months and these four months are adjacent to each other. Flowering in this species also has a commencement likelihood of 0.39 for two months: November and December. Those that do not have this can commence flowering in a large number of months (> 7months) (E. tricarpa, E. leucoxylon and E. macrorhyncha) and hence have a low value of likelihood of commencement. Eucalyptusgoniocalyx can commence in five months the same as E. polyanthemos but has the lowest value for flowering success $(0.58)$ and as a consequence fails to flower every 2.4 years. Note that E. leucoxylon has the highest flowering success rate (1.00) but still doesn't have a 11 or 12 month lag. GAMLSS ZIP analysis demonstrates the same contemporaneous effect of climate on flowering for $E$. tricarpa and E. leucoxylon, which constitutes one species pairing; for E. goniocalyx, E. microcarpa and E. macrorhyncha; and for E. camaldulensis, E.melliodora and E. polyanthemos, both species triples whose members were shown recently via wavelets to flower synchronously (Hudson et al. 2011a,b). GAMLSS are thus able to assist in delineating the unique climatic signatures for species which synchronise flowering. 
Hudson et al., Climate effects and thresholds for Eucalypt flowering: a GAMLSS ZIP approach

\section{REFERENCES}

Ashton DH (1975). The seasonal growth of Eucalyptus regnans F. Muell. Australian Journal of Botany 23, 239-252.

Beggs P. J. (2004) Impacts of climate change on aeroallergens: past and future. Clin. Exp. Allergy 34, 1507-13.

Borghi E, de Onis M, et al. (2006). WHO Child Growth Standards: Methods and Development. Statistics in Medicine 25, 247-265.

Chambers, L.E. and Keatley, M.R. (2010a). Phenology and Climate - early Australian botanical records. Australian Journal of Botany Vol 58(6), 473-484.

Chambers, L.E. and Keatley, M.R. (2010b) Australian Bird Phenology - a Search for Climate Signals. Austral Ecology Vol 35, 969-979

Fitter, A. H. and Fitter, R.S.R. (2002). Rapid changes in flowering time in British plants. Science 296, 168991.

Forrest, J. and Miller-Rushing, A.J. (2010). Toward a synthetic understanding of the role of phenology in ecology and evolution. Proc. Roy. Soc. London B 365, 3101-12.

Hudson, I. (2010a). Interdisciplinary approaches: towards new statistical methods for phenological studies. Clim Change 100(1):143-171.

Hudson, I.L. (2010b), Meta-analysis and its application in phenological research: a review and new statistical approaches, in Phenological Research: Methods for environmental and climate change analysis, I. L. Hudson and M. R. Keatley, Editors, pp. 463- 509. Springer, Dordrecht.

Hudson, I.L. (2011) Meta analysis, in Encyclopedia of Climate and Weather, S. H. Schneider, M. Mastrandrea and T. L. Root, Editors, pp 273-287. Oxford University Press., New York.

Hudson, I.L., Barnett A., Keatley, M.R., Ades, P.K. (2003). Investigation into drivers for flowering: effects of climate on flowering. In 'Proceedings of the 18th international workshop on statistical modelling', July 7-11 2003b, Katholieke Universiteit Leuven, Belgium. (Eds G Verbeke, G Moelenberghs, M Aaerts and S Fieuws), 195-200.

Hudson I.L., Kang, I., Keatley, M.R. (2010a).Wavelet Analysis of Flowering and Climatic Niche Identification. In: Hudson IL, Keatley MR (eds) Phenological Research: Methods for Environmental and Climate Change Analysis, Springer, pp 361-39.

Hudson, I. L. and Keatley, M. R. (2010a). Phenological Research: Methods for Environmental and Climate Change Analysis: Springer Dordrecht.

Hudson, I.L and Keatley, M.R. (2010b). Singular spectrum analysis: climatic niche identification. In 'Phenological Research: Methods for environmental and climate change analysis.' (Eds IL Hudson and MR Keatley) pp. 393-424. (Springer: Dordrecht).

Hudson, I.L., Keatley, M. R., Kang, I. (2010b).Wavelet characterization of eucalypt flowering and the influence of climate. Environmental and Ecological Statistics. Published first online 27 June, 2010. DOI: 10.1007/s10651-010-0149-5.

Hudson I.L., Keatley, M.R., Kang, I. (2011a). Wavelets and clustering: methods to assess synchronization. pp. 59-70. In: del Valle M, Muñoz R, Gutiérrez JM (eds) Wavelets: Classification, Theory and Applications. Nova Science Publishers

Hudson IL, Keatley, M.R., Kang I. (2011b). Wavelet Signatures of Climate and Flowering: Identification of Species Groupings In: Olkkonen H (ed) Discrete Wavelet Transforms / Book 2. InTech, Vienna (38pp).

Hudson, I.L., Keatley, M.R., Roberts, A.M.I. (2005). Statistical Methods in Phenological Research. In: Statistical Solutions to Modern Problems. Proceedings of the 20th International Workshop on Statistical Modelling (eds A. R. Francis, K. M. Matawie, A. Oshlack and G. K. Smyth) 10-15 July, 2005, pp. 25970, Sydney, Australia.

Hudson, I.L. Kim, S.W., Keatley, M.R. (2009). Climatic influences on the flowering phenology of four Eucalypts: a GAMLSS approach. In RS Anderssen, RD Braddock and LTH Newham eds Proceedings of the 18th International Association for Mathematics and Computers in Simulation (IMACS) / World Congress/MODSIM 2009, Cairns 13-17 July, 2009, pp 2611-2617

Hudson I.L., Kim S.W., Keatley M.R. (2010c). Climatic Influences on the Flowering Phenology of Four Eucalypts: A GAMLSS Approach. In: Hudson IL, Keatley MR (eds) Phenological Research: Methods for Environmental and Climate Change Analysis, Springer, Dordrecht, pp 209-228.

Hudson, I.L., Rea, A., Dalrymple, M. (2008). Climate impacts on Sudden Infant Death Syndrome: a GAMLSS approach. In 'Proceedings of the 23rd International Workshop on Statistical Modelling, July 711, 2008', 2008, Utrecht. (Ed. PH Eilers), pp. 277-280.

Keatley, M.R, Fletcher TD, Hudson, I.L., Ades, P.K. (2002). Phenological studies in Australia: Potential application in historical and future climate analysis. Intl Journal of Climatology 22(14), 1769-1780.

Keatley, M. and Hudson, I.L. (2000). Influences on the flowering phenology of three eucalypts. In 'Biometeorology and Urban Climatology at the Turn of the Century. Selected Papers from the Conference 
Hudson et al., Climate effects and thresholds for Eucalypt flowering: a GAMLSS ZIP approach

ICB-ICUC '99.' (Eds RJ de Dear, JD Kalma, TR Oke and A Aucliems) (World Meteorological Organisation: Geneva, Switzerland) pp. 191-196.

Keatley, M.R. and Hudson, I.L. (2007). A comparison of the long-term flowering patterns of Box-Ironbark species in Havelock and Rushworth forests. Environmental Modeling and Assessment 12, 279-292.

Keatley, M. R. and Hudson, I. L. (2010). Introduction and overview. In: Phenological Research: Methods for environmental and climate change analysis (eds I. L. Hudson and M. R. Keatley) pp. 1-22. Springer.

Keatley, M.R., Hudson, I.L., Fletcher, T.D. (1999). The use of long-term records for describing flowering behaviour: a case-study in Victorian Box-Ironbark Forests. In: Dargavel J, Wasser B (eds) Australia's Ever-changing Forests IV, Australian University Press, Canberra, pp 311-328.

Kim, S.W., Hudson, I.L., Keatley, M.R. (2011). Modelling lagged dependency of current and past climate on flowering: a mixture transition state approach, in International Congress of Biometeorology, Climate and Society, Dec., 4-8, 2011. University of Auckland, New Zealand (to appear).

Koch, E. (2000). Phenology in Austria: Phenological Mapping - Long-Term Trends, in Biometeorology and Urban Climatology at the Turn of the Century. Selected Papers from ICB-ICUC' 99, World Meteorological Organisation, Geneva, Switzerland, pp. 187-190.

Lambert, D. (1992). Zero-inflated Poisson regression with an application to defects in manufacturing. Technometrics, 34, 1-14.

Leith, H. (1974). Purposes of a phenology book. In: Phenology and Seasonality Modeling (ed H. Leith) pp. 3-19. Springer-Verlag, New York.

Loomis, R.S., Connor, D.J. (1992). 'Crop Ecology: Productivity and Management in Agricultural Systems.' (Cambridge University Press: Cambridge).

Mayer, D., Roy, D., Robbins, J., Halliday, I., Sellin, M. (2005). Modeling zero-inflated fish counts in estuaries-A comparison of alternate statistical distributions. In Zerger, A. and Argent, R. M. (eds) MODSIM 2005 International Congress on Modelling and Simulation, Dec., 2005, pp. 170-176.

Menzel, A., Sparks, T.H., et al. (2006). European phenological response to climate change matches the warming pattern. Global Change Biology 12(10), 1969 - 1976.

Nitschke, C.R., Hickey, G.M. (2007). Assessing the Vulnerability of Victoria's Central Highlands Forests to Climate Change. University of Melbourne, No. Technical Report 1/2007, Melbourne.

Porter, J.W. (1978). Relationships between flowering and honey production of Red Ironbark, Eucalyptus sideroxylon (A. Cunn.) Benth., and climate in the Bendigo district of Victoria. Australian Journal of Agricultural Research 29, 815-829.

Rehfeldt, G.E., Tchebakova, N.M., Parfenova, E.I. (2004). Genetic responses to climate and climate-change in conifers of the temperate and boreal forests. Recent Research Developments in Genetics and Breeding 1, 113-130.

Rigby, R.A., and Stasinopoulos, D.M. (2005), Generalized Additive Models for Location, Scale and Shape, Applied Statistics, 54, 507-554.

Rosenzweig, C., Karoly,D., et al. (2008). Attributing physical and biological impacts to anthropogenic climate change. Nature 453, 353-358.

Schwartz, M.D. (2000). Networking with Satellites: Perspectives on the Future of Phenology, in Biometeorology and Urban Climatology at the Turn of the Century. Selected Papers from the Conference ICB-ICUC' 99, World Meteorological Organisation, Geneva, Switzerland, pp. 169-174.

Snyder, R.L., Spano, D., Cesaraccio, C., Duce, P. (1999). Determining degree-day thresholds from field observations. International Journal of Biometeorology 42, 177-182.

Snyder, R.L., Spano, D., Duce, P., and Cesaraccio, C. (2001), Temperature for Phenological Models, Intl J Biometeorol, 45, 178-183.

Sparks, T.H., Croxton, P.J., Collinson, N., Taylor, P.W. (2005). Examples of phenological change, past and present, in UK farming. Annals of Applied Biology 146, 531-537.

Sparks, T.H., Jeffree, E.P., Jeffree, C.E. (2000). An examination of the relationship between flowering times and temperature at the national scale using long-term phenological records from the UK. International Journal of Biometeorology 44(2), 82-87.

Stasinopoulos, D.M., Rigby, R.A. (2007). Generalized Additive Models for Location Scale and Shape (GAMLSS) in R. Journal of Statistical Software 23(7), 1-46.

van Vliet, A. J. H. (2010). Societal adaptation options to changes in phenology. In: Phenological Research: Methods for environmental and climate change analysis (eds I. L. Hudson and M. R. Keatley) pp. 7598. Springer, Dordrecht.

Wielgolaski, F-E. (1999). Starting dates and basic temperatures in phenological observations of plants. International Journal of Biometeorology 42(3), 158-168.

Yang, S., Logan, J., Coffey, D.L. (1995). Mathematical formulae for calculating the base temperature for growing degree days. Agricultural and Forest Meteorology 74, 61-74. 